\title{
Error analysis of applicator position for combined internal/external radiation therapy in cervical cancer
}

\author{
WEI YING, LI LIANG, YU WANG and GUO-HAI QI \\ Radiotherapy Center, Sichuan Cancer Hospital and Institue, Sichuan Cancer Center, School of Medicine, \\ University of Electronic Science and Technology of China, Chengdu, Sichuan 610041, P.R. China
}

Received April 10, 2017; Accepted September 4, 2017

DOI: $10.3892 / \mathrm{ol} .2018 .9061$

\begin{abstract}
The aim of this study was to analyze the error variation in the applicator placement during the first and second radiotherapy session for cervical cancer. We recruited 22 patients with cervical cancer treated with radiotherapy. According to the image output in the first and second CT-Sim inspection, we conducted comparative analysis of image fusion to accurately measure the errors in applicator position in the horizontal (X-), longitudinal (Y-) and vertical (Z)-axes. The calibration processing was implemented in accordance with the data error measured and the location parameters, such as the angle and depth of the applicator. Electronic portal imaging technology (EPID) was used to calibrate posture change amplitude for the extracorporeal irradiation of patients, and dynamic measurement with applicator position was used to describe the error of the parameters. Finally, the data from two measurements in CT-Sim, digital reconstruction radiography (DRR) and EPID were compared. After calibration, the mean value of error of the applicator were significantly smaller. Image registration planning for error parameter calibration of applicator position can effectively reduce the applied horizontal spatial position error in radiotherapy treatment, and improve the accuracy and effectiveness during treatment.
\end{abstract}

\section{Introduction}

Cervical cancer is one of the most common malignant tumors in the modern gynecological clinical practice, which seriously affects the life and health of patients and their quality of life (1). Uterine cavity brachytherapy and intensity modulated radiation therapy (IMRT) is a basic clinical treatment for cervical cancer(2). In recent years, the application of modern image-guided technology has been widely used in brachytherapy of cervical cancer patients. However, during radiotherapy, the applicator position is prone to error. If the error is relatively large, the accuracy and

Correspondence to: Dr Guo-Hai Qi, Radiotherapy Center, Sichuan Cancer Hospital and Institue, Sichuan Cancer Center, School of Medicine, University of Electronic Science and Technology of China, 55 Renmin South Road, 4th Section, Chengdu, Sichuan 610041, P.R. China

E-mail: um2444042@163.com

Key words: cervical cancer, irradiation, applicator, position error effectiveness of the treatment are affected (3-5). Here, we discuss the error in applicator position in after-loading combined radiation therapy for cervical cancer for the first and second sessions to provide valuable reference to enhance the therapeutic effect of irradiation in patients with cervical cancer.

\section{Materials and methods}

Patient information. We recruited 22 cases of cervical cancer treated with radiotherapy in Sichuan Cancer Hospital and Institute (Chengdu, China) from November 2013 to January 2016. The patients were aged 25-72 years, with a mean age of $47.1 \pm 4.4$ years. Clinical stages: IIb 7 cases, IIIa 9 cases, and IIIb 6 cases. Pathological type: 17 cases of phosphate cell carcinoma and 5 cases of adenocarcinoma. The study was approved by the Ethics Committee of Sichuan Cancer Hospital and Institute and written informed consents were signed by the patients and/or guardians.

Methods. Main instruments and equipment: GE64 spiral CT (CT-Sim), Nucletron Simulix-HP simulated locator, Varian Clinac 23EX linear accelerator, Oncentra MasterPlan 3.2 nucletron after-loading planning application system, and the Fletcher applicator.

Main treatments: The main links for the radiation therapy are the evacuation routes of rectal and bladder physiology, manufacture of vacuum pad and bulk film, and the installation place of the applicator. Normal saline $(250 \mathrm{ml})$ was injected into the bladder of the patients. CT-Sim scan, regional delineation of target location for radiotherapy treatment (Figs. 1 and 2), scheme design and planning DRR image registration, intra cavity radiation therapy, electronic portal imaging technology (EPID) results, in vitro radiation therapy, EPID images, DRR images fusion (Fig. 3), and the statistics of error position of the applicator equipment. We also implemented image fusion processing, applicator position parameter calibration, and setup verification and other processing technology.

Statistical analysis. IBM SPSS 19.0 (Armonk, NY, USA) was used for all statistical analysis. Measurement data were expressed as mean $\pm \mathrm{SD}$. The comparison among multiple groups was performed using ANOVA and the post hoc was Dunnett's test. $\mathrm{P}<0.05$ was considered to indicate a statistically significant difference. 


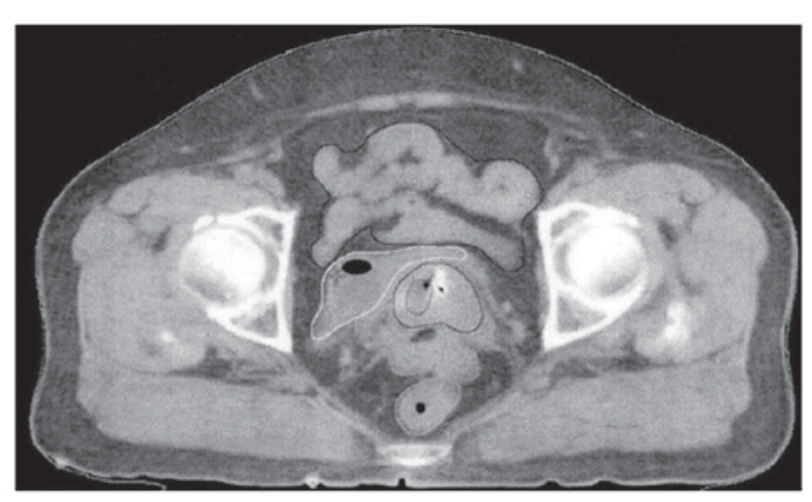

Figure 1. Outline of target location area in radiotherapy.

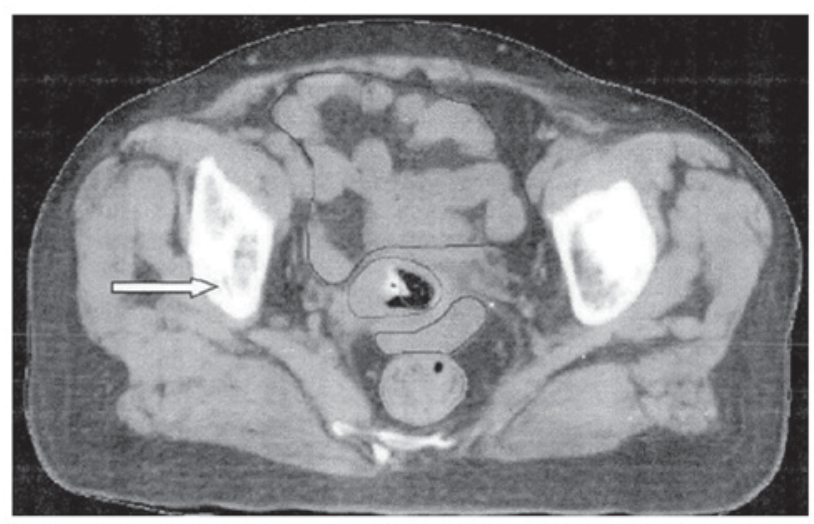

Figure 2. CT images of the visible cervical markers (white arrow).

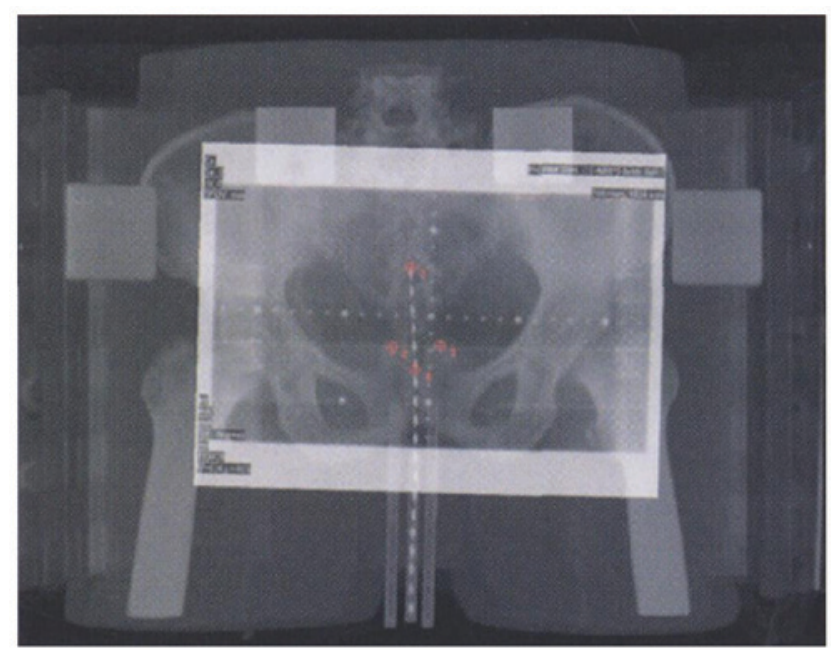

Figure 3. Electronic portal imaging technology (EPID) image and DRR image fusion processing.

\section{Results}

Comparison of the first and second CT-Sim fusion in the 22 patients in this cohort is shown in Fig. 4. After parameter error calibration, applicator position errors are shown in Tables I and II. Before calibration, the mean values of error of the applicator in the horizontal (X-), longitudinal (Y-) and vertical (Z)-axes were 5.301, 5.216 and $2.576 \mathrm{~mm}$, respectively, with relatively large errors (Table I). After calibration, the mean value of error of the
Table I. Error parameters of applicator position of the first and second CT-Sim scan fusion.

\begin{tabular}{lccccc}
\hline $\begin{array}{l}\text { Error } \\
(\mathrm{mm})\end{array}$ & $\begin{array}{l}\text { Mean } \\
\text { value }\end{array}$ & $\begin{array}{c}\text { Standard } \\
\text { deviation }\end{array}$ & $\begin{array}{c}\text { Standard } \\
\text { error }\end{array}$ & $\begin{array}{c}95 \% \mathrm{CL} \\
\text { lower limit }\end{array}$ & $\begin{array}{c}95 \% \mathrm{CL} \\
\text { upper limit }\end{array}$ \\
\hline X-direction & 5.301 & 0.2696 & 0.0604 & 5.175 & 5.427 \\
Y-direction & 5.216 & 0.1928 & 0.0432 & 5.126 & 5.306 \\
Z-direction & 2.576 & 0.2338 & 0.0524 & 2.467 & 5.685 \\
P-value & $<0.05$ & & & & \\
\hline
\end{tabular}

X, horizontal; Y, longitudinal; Z, vertical.

Table II. Error parameters of applicator position after calibration.

\begin{tabular}{lccccc}
\hline $\begin{array}{l}\text { Error } \\
(\mathrm{mm})\end{array}$ & $\begin{array}{l}\text { Mean } \\
\text { value }\end{array}$ & $\begin{array}{c}\text { Standard } \\
\text { deviation }\end{array}$ & $\begin{array}{c}\text { Standard } \\
\text { error }\end{array}$ & $\begin{array}{c}\text { 95\% CL } \\
\text { lower limit }\end{array}$ & $\begin{array}{c}95 \% \text { CL } \\
\text { upper limit }\end{array}$ \\
\hline X-direction & 1.876 & 0.1294 & 0.290 & 1.8151 & 1.936 \\
Y-direction & 2.191 & 0.2031 & 0.0451 & 2.0901 & 2.281 \\
Z-direction & 1.821 & 0.1362 & 0.0305 & 1.7561 & 1.885 \\
P-value & $<0.05$ & & & & \\
\hline
\end{tabular}

X, horizontal; Y, longitudinal; Z, vertical.
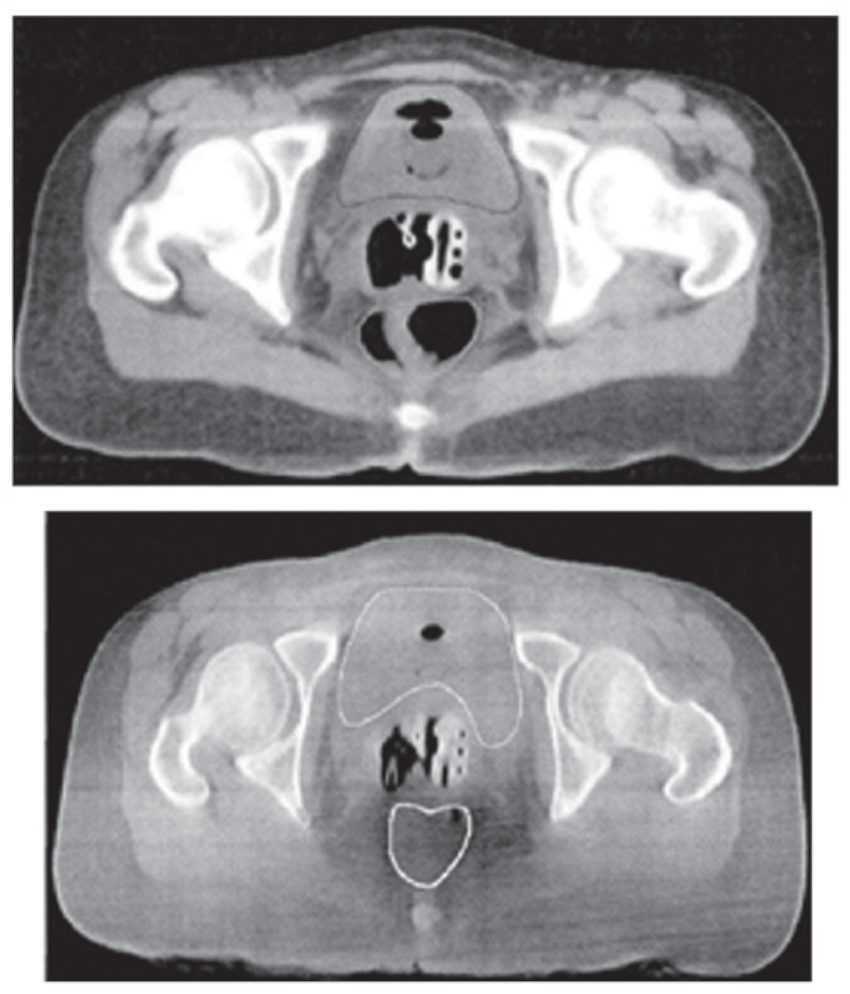

Figure 4. Fusion of first and second CT-Sim scans.

applicator in X-, Y- and Z-axes were 1.876, 2.191 and $1.821 \mathrm{~mm}$, respectively, and the errors were significantly smaller.

The results of EPID and DRR image indicate that, in the process of radiation therapy metastasis, the position errors of 
applicator on the direction of X-, Y- and Z-axes were less than $2.0 \mathrm{~mm}$ for the 22 cases of patients (Fig. 4). The errors of applicator before and after calibration had statistical significance $(\mathrm{P}<0.05)$.

\section{Discussion}

Cervical cancer is a common gynecological malignant tumor, and its clinical incidence is only second to breast cancer (6-8). Study shows that when cervical cancer patients receive timely, effective, and systematic radiation therapy, the 5-year survival rate can be increased to $45-51 \%(9-12)$. In recent years, with the rapid development of medical radiation in China, traditional radiotherapy technology has gradually been replaced by three-dimensional conformal radiotherapy and other modern treatment technologies. In this context, the influence of applicator position error on the final treatment effectiveness has gradually aroused widespread concern (13-17).

The present study shows that, before calibration, the mean values of errors of the applicator in the X-, Y- and Z-axes had relatively large errors. After calibration, the mean values of error of the applicator in X-, Y- and Z-axes were significantly smaller. After the first and second CT-Sim contrast fusion, DR diagram and implementation of DRR registration of treatment plan, the parameter error of applicator position becomes small. Further analysis showed that the change of position of the applicator after registration was concentrated near the bilateral ovoid. The possible reasons are that location corresponds to the anatomical location is the vaginal fornix, and the structure of this position is flabby. During gauze packing in the surgery, it is easy to change the applicator position by the change of the dome shape $(18,19)$. Another reason may be that after the completion of the filling surgery, when the vagina speculum is removed, because the tension change makes the vagina space change, the applicator position changes significantly $(20,21)$.

In conclusion image registration technique of radiotherapy planning for error parameter calibration processing can reduce the horizontal spatial error of applicator position, and improve the accuracy and effectiveness during treatment in the treatment of cervical cancer with intracavity and in vitro combined radiotherapy. These advantages make this technique worthy of promotion.

\section{Competing interests}

The authors declare that they have no competing interests.

\section{References}

1. Hoskin PJ: Hypoxia dose painting in prostate and cervix cancer. Acta Oncol 54: 1259-1262, 2015.

2. Assenholt MS, Vestergaard A, Kallehauge JF, Mohamed S, Nielsen SK, Petersen JB, Fokdal L, Lindegaard JC and Tanderup K Proof of principle: Applicator-guided stereotactic IMRT boost in combination with 3D MRI-based brachytherapy in locally advanced cervical cancer. Brachytherapy 13: 361-368, 2014.

3. Blanco AI, Meyer LA, George V, Teh BS, Rios A, Ferachi K, Rodriguez M, Gonzalez A and Dalrymple J: The use of modern imaging technologies in radiation therapy of cervical cancer. J Radiat Oncol 4: 1-10, 2015.

4. Dimopoulos JC, Kirisits C, Petric P, Georg P, Lang S, Berger D and Pötter R: The Vienna applicator for combined intracavitary and interstitial brachytherapy of cervical cancer: Clinical feasibility and preliminary results. Int J Radiat Oncol Biol Phys 66: 83-90, 2006.
5. Hashim N, Jamalludin Z, Ung NM, Ho GF, Malik RA and Phua VC: CT based 3-dimensional treatment planning of intracavitary brachytherapy for cancer of the cervix: Comparison between dose-volume histograms and ICRU point doses to the rectum and bladder. Asian Pac J Cancer Prev 15: 5259-5264, 2014.

6. Ma JK, Mourad WF, Allbright R, Packianathan S, Harrell LM Chinchar E, Nguyen A and Vijayakumar S: Short-term clinical outcome and dosimetric comparison of tandem and ring versus tandem and ovoids intracavitary applicators. J Contemp Brachytherapy 7: 218-223, 2015.

7. Salcedo MP, Milbourne AM, Jhingran A, Eifel PJ, Ramirez PT and Schmeler KM: High-grade cervical dysplasia following radiation therapy for invasive cervical cancer: A report of four cases. Case Rep Oncol 8: 217-221, 2015.

8. Klopp A, Mourtada F, Yu Z, Beadle B, Lawyer A, Jhingran A and Eifel P: Pilot study of a new ct-compatible intracavitary brachytherapy applicator for treatment of cervical cancer. Brachytherapy 9: 115-123, 2010.

9. Ghose S, Holloway L, Lim K, Chan P, Veera J, Vinod SK, Liney G, Greer PB and Dowling J: A review of segmentation and deformable registration methods applied to adaptive cervical cancer radiation therapy treatment planning. Artif Intell Med 64: 75-87, 2015.

10. Ghadjar P, Budach V, Köhler C, Jantke A and Marnitz S: Modern radiation therapy and potential fertility preservation strategies in patients with cervical cancer undergoing chemoradiation. Radiat Oncol 10: 50, 2015.

11. Low DA, Grigsby PW, Dempsey JF, Mutic S, Williamson JF, Markman J, Chao KS, Klein EE and Purdy JA: Applicator-guided intensity-modulated radiation therapy. Int J Radiat Oncol Biol Phys 52: 1400-1406, 2002.

12. Chakraborty S, Geetha M, Dessai S and Patil VM: How well do elderly patients with cervical cancer tolerate definitive radiochemotherapy using RapidArc? Results from an institutional audit comparing elderly versus younger patients. E Cancer Med Sci 8: 484, 2014.

13. Yong JS, Ung NM, Jamalludin Z, Malik RA, Wong JH, Liew YM and Ng KH: Dosimetric impact of applicator displacement during high dose rate (hdr) cobalt-60 brachytherapy for cervical cancer: A planning study. Radiat Phys Chem 11: 264-271, 2016.

14. Rezaeealam B: Applicator modeling for electromagnetic thermotherapy of cervix cancer. Electromagn Biol Med 34: 43-47, 2015.

15. Thompson SR, Delaney GP, Gabriel GS and Barton MB: Patterns of care study of brachytherapy in New South Wales: Cervical cancer treatment quality depends on caseload. J Contemp Brachytherapy 6: 28-32, 2014.

16. Nomden CN, de Leeuw AA, Moerland MA, Roesink JM, Tersteeg RJ and Jürgenliemk-Schulz IM: Clinical use of the Utrecht applicator for combined intracavitary/interstitial brachytherapy treatment in locally advanced cervical cancer. Int J Radiat Oncol Biol Phys 82: 1424-1430, 2012.

17. Kirchheiner K, Nout RA, Lindegaard JC, Haie-Meder C, Mahantshetty U, Segedin B, Jürgenliemk-Schulz IM, Hoskin PJ, Rai B, Dörr W, et al; EMBRACE Collaborative Group: Dose-effect relationship and risk factors for vaginal stenosis after definitive radio(chemo)therapy with image-guided brachytherapy for locally advanced cervical cancer in the EMBRACE study. Radiother Oncol 118: 160-166, 2016.

18. Dewitt KD, Hsu IC, Speight J, Weinberg VK, Lessard E and Pouliot J: 3D inverse treatment planning for the tandem and ovoid applicator in cervical cancer. Int J Radiat Oncol Biol Phys 63: 1270-1274, 2005.

19. Petric P, Hudej R, Hanuna O, Marolt P, Al-Hammadi NM, Riyas MP and Segedin B: MRI-assisted cervix cancer brachytherapy pre-planning, based on application in paracervical anaesthesia: Final report. Radiol Oncol 48: 293-300, 2014.

20. Mazeron R, Castelnau-Marchand P, Dumas I, del Campo ER, Kom LK, Martinetti F, Farha G, Tailleur A, Morice P, Chargari C, et al: Impact of treatment time and dose escalation on local control in locally advanced cervical cancer treated by chemoradiation and image-guided pulsed-dose rate adaptive brachytherapy. Radiother Oncol 114: 257-263, 2015.

21. Yin G, Wang P, Lang J, Tian Y, Luo Y, Fan Z and Tam KY: Dosimetric study for cervix carcinoma treatment using intensity modulated radiation therapy (IMRT) compensation based on 3D intracavitary brachytherapy technique. J Contemp Brachytherapy 8: 221-232, 2016.

This work is licensed under a Creative Commons Attribution-NonCommercial-NoDerivatives 4.0 International (CC BY-NC-ND 4.0) License. 